\title{
Combination antiretroviral therapy and duration of pregnancy
}

\section{The European Collaborative Study and the Swiss Mother + Child HIV Cohort Study*}

\begin{abstract}
Objective: To assess the association between type and timing of initiation of antiretroviral therapy in pregnancy and duration of pregnancy.

Design: Prospective study.

Methods: Data on 3920 mother-child pairs were examined (3015 mother-child pairs from the European Collaborative Study and 905 from the Swiss Mother + Child HIV Cohort Study). Factors examined included gestational age, antiretroviral therapy during pregnancy, maternal CD4 count, viral load, illicit drug use (IDU) and mode of delivery. Deliveries at less than 37 weeks were defined as premature.

Results: The prematurity rate was $17 \%$ and median gestational age 39 weeks. Twentythree per cent (896 of 3920) of women received antiretroviral therapy during pregnancy: $64 \%$ (573 of 896 ) zidovudine monotherapy, $24 \%$ (215) combination therapy without protease inhibitors (PI) and 12\% (108) combination therapy with PI. In multivariate analysis, adjusted for maternal CD4 count and IDU, odds ratio (OR) of prematurity was 2.60 [95\% confidence interval $(\mathrm{Cl}), 1.43-4.75]$ and $1.82(95 \% \mathrm{Cl}$, 1.13-2.92) for infants exposed to combination therapy with and without a Pl, respectively, compared to no treatment. Exposure to monotherapy was not associated with prematurity, but severe immunosuppression and IDU in pregnancy were. Women on combination therapy from before pregnancy were twice as likely to deliver prematurely as those starting therapy in the third trimester $(\mathrm{OR}, 2.17 ; 95 \% \mathrm{Cl}, 1.03-$ 4.58).
\end{abstract}

Conclusions: Pregnancy issues should be discussed when making decisions about initiation of combination antiretroviral therapy for HIV-infected women. Elective caesarean section to reduce vertical transmission at 36 weeks rather than 38 weeks may be advisable in women on combination therapy with PI.

(c) 2000 Lippincott Williams \& Wilkins

AIDS 2000, 14:2913-2920

Keywords: Antiretroviral therapy, combination therapy, epidemiology, prematurity, pregnancy

\section{Introduction}

Risk of mother-to-child transmission of HIV-1 infection can be reduced by prophylactic antiretroviral therapy during pregnancy, delivery and in the neonatal period, elective caesarean section delivery and refrain- ing from breastfeeding [1]. A combination of these three interventions is now commonly used and transmission rates as low as $1 \%$ have been achieved [2-4]. Increasing numbers of women are now taking combination therapy in pregnancy both in the USA and Europe [5-7]. Current recommendations do not in-

From the Department of Paediatric Epidemiology and Biostatistics, Institute of Child Health, 30 Guilford Street, London, WC1N $1 \mathrm{EH}$, UK. * Prepared by Claire Thorne, Christoph Rudin, Marie-Louise Newell, Christian Kind, Irène Hug, Linsay Gray and Catherine S. Peckham; also see Appendix.

Correspondence to Dr Marie-Louise Newell, Department of Paediatric Epidemiology and Biostatistics, Institute of Child Health, 30 Guilford Street, London, WC1N 1EH, UK.

Tel: +44 207829 8699; fax: +44 207813 8145; e-mail: M.Newell@ich.ucl.ac.uk

Received: 27 June 2000; revised: 18 August 2000; accepted: 23 August 2000. 
clude specific guidelines on the use of combination therapy in pregnancy, instead providing general principles for the use of antiretrovirals in pregnancy $[1,8]$.

However, questions remain regarding the potential adverse effects of antiretroviral therapy in pregnancy. Exposure to antiretroviral therapy in fetal or early life has in rare cases been associated with mitochondrial abnormalities [9], but causality is difficult to prove. Although there is no evidence to date that exposure to antiretroviral therapy in pregnancy is associated with congenital abnormalities or later development of cancers $[10,11]$, one child with extrahepatic biliary atresia, one with congenital glaucoma and one intracerebral haemorrhage at term were reported among 95 children exposed to combined antiretroviral therapy in the Swiss Cohort [5, C. Rudin, personal communication, 2000]. However, the number of exposed children and duration of follow-up are limited, and the effect of newer drug combinations uncertain. Evidence is lacking regarding the effect of antiretroviral therapy on pregnancy outcomes such as spontaneous abortions, stillbirths or premature deliveries.

In the European Collaborative Study (ECS), prophylactic zidovudine monotherapy was associated with a decreased risk of low birthweight and prematurity in a cohort of $2300 \mathrm{HIV}$-infected women [12], whereas in the Swiss cohort, there was an increased risk of premature deliveries in 37 women treated with two or more antiretroviral agents [5]. To further explore the relationship between type and timing of initiation of antiretroviral therapy and prematurity, data from the ECS and the Swiss cohorts were combined.

\section{Methods}

The Swiss Mother + Child HIV Cohort Study (MoCHiV) and the ECS are prospective studies, using similar protocols to follow-up infants born to HIVinfected women. The ECS, set up in 1986, includes 26 centres in nine European countries [2,13]. The Swiss study was formed in 1998 following a merger of the Swiss Neonatal HIV Study and the Swiss Collaborative HIV and Pregnancy Study, active since 1986 and 1989 respectively [4]. Informed consent is obtained, and ethics approval has been granted.

Information is collected on type and timing of initiation of antiretroviral therapy, maternal CD4 count and viral load during pregnancy [14], mother's illicit drug use and other socio-demographic variables, mode of delivery, gestational age and neonatal characteristics. Gestational age was confirmed by ultrasound and reported to the nearest completed week. Premature delivery was defined as delivery before 37 weeks of gestation.
In the ECS, maternal viral load and CD4 count were determined locally, with type of assay recorded. In the Swiss study laboratory tests were carried out in dedicated reference centres with quality control by the Swiss HIV Cohort Study [14]. Most (79\%) tests were carried out within the third trimester or up to 2 weeks after delivery, and where multiple tests were available that nearest delivery was used. Assay types used were Roche (Amplicor Monitor, version 1.0; Roche Diagnostic Systems, Basel, Switzerland), NASBA and Nuclisens (Organon Teknika, Oss, Holland); tests were usually carried out on plasma samples, but occasionally on stored serum samples [2]. For each combination of sample type (i.e. plasma or serum) and assay type, the median was calculated, which was used to create the summary variable of HIV RNA copy number [2]. Where used as a continuous variable, RNA viral load level was $\log$ transformed.

Univariate comparisons for categorized variables were tested with $\chi^{2}$ test or $\chi^{2}$ test for linear trend. Logistic regression was used to obtain odds ratios (OR) and 95\% confidence intervals (CI), both univariate and adjusted for potential confounders. Analyses were performed using SAS statistical software (version 6.12; SAS Institute, Cary, North Carolina, USA).

The logistic regression analysis included the following factors: maternal CD4 count (categorized into three variables: $<200,200-499, \geqslant 500 \times 10^{6}$ cells/l), illicit drug use in pregnancy $(\mathrm{Y} / \mathrm{N})$ and type of antiretroviral therapy in pregnancy [none, monotherapy, combination therapy without protease inhibitor (PI), combination therapy with PI]. We performed a total of five separate multivariate analyses: (1) for all mother-child pairs with information on gestational age at delivery, CD4 count, drug use and antiretroviral therapy; (2) including all the variables in analysis (1), plus maternal age (categorized into three variables: $<25$ years, $25-$ 29 years, $\geqslant 30$ years) and parity (categorized into four variables: $0,1,2, \geqslant 3$ ); (3) repeat of analysis (1), excluding all deliveries by elective caesarean section; (4) repeat of analysis (1), using ECS data only and (5) repeat of analysis (1), using MoCHiV data only. A dummy variable was created to investigate the existence of any significant differences in prematurity between the ECS and the MoCHIV cohorts in multivariate analysis. The possibility of a differential treatment effect on prematurity between cohorts was investigated using an interaction term in multivariate analysis.

\section{Results}

By April 2000, 3920 mother-child pairs were available, 3015 in the ECS and 905 in MoCHiV. Prematurity rates in the MoCHiV, 16\% (132 of 836), and ECS, 
$17 \%$ (476 of 2829), were similar, as was the distribution of maternal and delivery characteristics. The prematurity rate overall was $17 \%$ (Table 1) and median gestational age 39 weeks (range, 25-43 weeks). Thirty-one per cent of infants $(n=1215)$ were born since January 1995.

Less than a quarter (896 of 3920, 23\%) of women had received antiretroviral therapy during pregnancy, mostly (573 of 896, 64\%) zidovudine monotherapy (Table 1). The majority of women received antiretroviral therapy as prophylaxis to reduce vertical transmis-

Table 1. Maternal and delivery characteristics.

\begin{tabular}{|c|c|c|}
\hline & $\mathrm{n}$ & $\%$ \\
\hline \multicolumn{3}{|l|}{ Maternal age at delivery $(\mathrm{n}=3613)$} \\
\hline$<25$ years & 1095 & 30 \\
\hline $25-29$ years & 1110 & 40 \\
\hline$\geqslant 30$ years & 1075 & 30 \\
\hline \multicolumn{3}{|c|}{ CD4 cell count $\left(\times 10^{6}\right.$ cells $\left./ l\right)(n=1510)$} \\
\hline$<200$ & 239 & 16 \\
\hline $200-499$ & 689 & 46 \\
\hline$\geqslant 500$ & 582 & 38 \\
\hline \multicolumn{3}{|c|}{ Viral load (RNA copy number) $(n=530)$} \\
\hline Undetectable & 230 & 43 \\
\hline Below median ${ }^{\mathrm{a}}$ & 145 & 27 \\
\hline Above median ${ }^{\mathrm{a}}$ & 155 & 29 \\
\hline \multicolumn{3}{|c|}{ Illicit drug use in pregnancy $(n=3407)$} \\
\hline No & 2577 & 76 \\
\hline Yes & 830 & 24 \\
\hline \multicolumn{3}{|c|}{ Antiretroviral therapy in pregnancy $(n=3920)$} \\
\hline None & 3024 & 77 \\
\hline Monotherapy & 573 & 15 \\
\hline Combination therapy: no PI & 215 & 5 \\
\hline Combination therapy: with PI & 108 & 3 \\
\hline \multicolumn{3}{|c|}{ Timing of initiation of antiretroviral therapy $(n=707)$} \\
\hline Pre-pregnancy & 111 & 16 \\
\hline First trimester & 34 & 5 \\
\hline Second trimester & 238 & 34 \\
\hline Third trimester & 324 & 46 \\
\hline \multicolumn{3}{|l|}{ Premature delivery $(\mathrm{n}=3665)$} \\
\hline No & 3057 & 83 \\
\hline Yes & 608 & 17 \\
\hline \multicolumn{3}{|c|}{ Elective caesarean section $(n=3870)$} \\
\hline No & 2878 & 74 \\
\hline Yes & 992 & 26 \\
\hline
\end{tabular}

${ }^{\text {a }}$ For assay and sample type. PI, protease inhibitor. sion and were clinically and immunologically well at the time of initiation. The 323 women taking combination therapy most commonly received zidovudine plus lamivudine (132 cases, 41\%). Other nucleoside reverse transcriptase inhibitors (NRTIs) taken were zalcitabine, didanosine, stavudine and abacavir. Nelfinavir was the most frequently used PI, used in 64 of 108 (59\%) PI-containing combination regimens. Thirty-eight women (12\%) took indinavir in pregnancy and a few took saquinavir and ritonavir.

Maternal RNA viral load when categorized was not associated with prematurity, with prematurity rates of 19\% (27 of 142) and 21\% (31 of 151) for mothers with RNA viral load below and above the median respectively $(P=0.745)$. Simple linear regression analysis (excluding women with elective caesarean section) showed a slight negative association between gestational age and $\log$ maternal RNA viral load $(P=0.149)$. In Table 2, prematurity rates for each treatment group are presented, stratified by maternal CD4 count (in three categories). There was a consistently higher prematurity rate in the combination therapy with PI treatment group compared with the no treatment and monotherapy groups across the three immunological categories.

Maternal CD4 cell count, illicit drug use in pregnancy and combination antiretroviral therapy in pregnancy were individually significantly related to prematurity (Table 3). For example, prematurity rates were $22 \%$ among infants born to women with CD4 cell counts below $200 \times 10^{6}$ cells $/ 1,24 \%$ among those whose mothers had actively used illicit drugs in pregnancy and $29 \%$ among those exposed to combination therapy with a PI. A logistic regression analysis included 1444 mother-child pairs with information on maternal CD4 count, illicit drug use in pregnancy and antiretroviral therapy, with premature delivery as the dependent variable (Table 3). The characteristics of women with and without information on all four variables were similar. Maternal CD4 count was included in the model rather than viral load, because HIV RNA copy number was not strongly associated with gestational age or prematurity in univariate analysis; and fewer than

Table 2. Prematurity rates, by treatment in pregnancy, stratified by CD4 cell count.

\begin{tabular}{|c|c|c|c|c|c|c|}
\hline & \multicolumn{6}{|c|}{ Maternal CD4 cell count } \\
\hline & \multicolumn{2}{|c|}{$<200 \times 10^{6}$ cells $/ \mathrm{l}$} & \multicolumn{2}{|c|}{$200-499 \times 10^{6}$ cells/l } & \multicolumn{2}{|c|}{$\geqslant 500 \times 10^{6} \mathrm{cells} / \mathrm{l}$} \\
\hline & $\begin{array}{c}<37 \text { weeks } \\
\mathrm{n}(\%)\end{array}$ & $\begin{array}{c}\geqslant 37 \text { weeks } \\
\mathrm{n}(\%)\end{array}$ & $\begin{array}{c}<37 \text { weeks } \\
\mathrm{n}(\%)\end{array}$ & $\begin{array}{c}\geqslant 37 \text { weeks } \\
\mathrm{n}(\%)\end{array}$ & $\begin{array}{c}<37 \text { weeks } \\
\mathrm{n}(\%)\end{array}$ & $\begin{array}{c}\geqslant 37 \text { weeks } \\
\mathrm{n}(\%)\end{array}$ \\
\hline No treatment & $31(23)$ & $104(77)$ & $60(15)$ & $353(85)$ & $45(12)$ & $346(88)$ \\
\hline Monotherapy & $11(16)$ & $56(84)$ & $20(14)$ & $125(86)$ & $13(12)$ & $96(88)$ \\
\hline Combination therapy without PI & $3(20)$ & $12(80)$ & $16(22)$ & $56(78)$ & $8(22)$ & $28(78)$ \\
\hline Combination therapy with PI & $4(50)$ & $4(50)$ & $8(24)$ & $25(76)$ & $5(23)$ & $17(77)$ \\
\hline
\end{tabular}

$\mathrm{PI}$, protease inhibitor. 
400 mother-child pairs would have been included in the analysis, severely limiting its power.

Exposure to combination antiretroviral therapy increased risk of premature delivery independent of maternal CD4 count and illicit drug use. Infants exposed to antiretroviral therapy with a PI were 2.6 times more likely to be born prematurely compared with those unexposed, with a lower but significantly increased risk for those exposed to antiretroviral therapy involving only NRTIs (Table 3). Exposure to monotherapy was not significantly associated with duration of pregnancy. Severely immunocompromised women (CD4 cell count $<200 \times 10^{6}$ cells/l) and those actively using illicit drugs (mainly heroin or methadone) were also significantly more likely to deliver before 37 weeks gestation. We repeated the logistic regression analysis to include maternal age and parity, which had no substantial impact on the effect of antiretroviral therapy on risk of premature delivery. As elective caesarean section is recommended for HIV-infected women, we repeated the analysis with the 974 women delivered vaginally or by emergency caesarean section. The results were substantially similar with a somewhat larger effect of combination therapy on the risk of prematurity. Analyses were also carried out for the ECS and MoCHiV separately, with similar results. There was no significant difference between the two cohorts in multivariate analysis [adjusted odds ratio (AOR), $1.05 ; 95 \%$ confidence interval (CI), 0.73-1.51; $P=0.805]$, nor evidence that the effect of treatment on prematurity differed by cohort. A re-parameterized multivariate analysis including combination therapy with a PI as baseline treatment group showed that combination therapy without a PI did not differ significantly from combination therapy with a PI in predicting prematurity (AOR, 0.70; 95\% CI, 0.34$1.42 ; P=0.323)$.

Prematurity rates by type and timing of antiretroviral therapy are presented in Table 4. Although risk of prematurity was always high among women treated with combination therapy with PIs, it was greatest where antiretroviral therapy was initiated before and retained throughout pregnancy or started in the first trimester (16 of 40,40\%), compared with initiation of antiretroviral therapy in the second and third trimesters (10 of $56,18 \%)\left(\chi^{2}=5.73, P=0.030\right)$. In logistic regression analysis, women on combination therapy (with or without PIs) from before pregnancy were twice as likely to deliver prematurely as those who started in the third trimester $(\mathrm{OR}, 2.17 ; 95 \% \mathrm{CI}$, 1.03-4.58; $P=0.043)$.

To further investigate how treatment regimen was associated with gestational age, the cumulative distribution of gestational age at delivery by treatment group was plotted, excluding elective caesarean section deliveries (Fig. 1). Although most untreated women delivered at 40 weeks gestation, there was a shift towards earlier delivery for all treatment groups, but no evidence of an abrupt change. By 37 weeks, $16 \%$ of the untreated, $17 \%$ of the monotherapy group, $22 \%$ of the antiretroviral therapy without PI and $29 \%$ of the antiretroviral therapy with PI group had delivered. From Kaplan-Meier analysis, gestational age at delivery varied significantly by treatment group (log rank $\left.\chi_{(3)}^{2}=129.4 ; \quad P<0.001\right)$. Overall, birthweight was appropriate for gestational age. There were no significant differences between mean birthweights by treatment group (no/monotherapy versus combination therapy) for premature infants, with means of $2170 \mathrm{~g}$ and 2233 g respectively $(P=0.446)$.

Table 3. Maternal factors and prematurity.

\begin{tabular}{|c|c|c|c|c|}
\hline & \multicolumn{2}{|c|}{ Premature delivery } & \multirow{2}{*}{$\begin{array}{c}\text { Univariate odds ratio } \\
\qquad(95 \% \mathrm{Cl})\end{array}$} & \multirow{2}{*}{$\begin{array}{c}\text { Multivariate odds ratio* } \\
\qquad(95 \% \mathrm{Cl})\end{array}$} \\
\hline & No $(\%)$ & Yes (\%) & & \\
\hline \multicolumn{5}{|l|}{ CD4 cell count $\left(\times 10^{6}\right.$ cells $\left./ \mathrm{l}\right)$} \\
\hline$\geqslant 500$ & $487(87)$ & $71(13)$ & 1.00 & 1.00 \\
\hline $200-499$ & $559(84)$ & $105(16)$ & $0.96(0.76-1.21) \mathrm{NS}$ & $1.23(0.88-1.71)$ \\
\hline$<200$ & $176(78)$ & $49(22)$ & $1.42(1.02-1.99) P=0.03$ & $1.93(1.28-2.91) P<0.02$ \\
\hline \multicolumn{5}{|c|}{$\chi^{2}=10.1, P=0.006$} \\
\hline \multicolumn{5}{|l|}{ Injecting drug use during pregnancy } \\
\hline No & $2087(85)$ & $360(15)$ & 1.00 & 1.00 \\
\hline \multicolumn{5}{|c|}{$\chi^{2}=37.0, P<0.001$} \\
\hline Antiretroviral therapy in pregnan & & & & \\
\hline None & $2375(84)$ & $444(16)$ & 1.00 & 1.00 \\
\hline Monotherapy & $462(83)$ & $93(17)$ & $1.08(0.84-1.38) \mathrm{NS}$ & $1.03(0.70-1.50) \mathrm{NS}$ \\
\hline Combination therapy: no PI & $147(78)$ & $41(22)$ & $1.49(1.04-2.14) P<0.05$ & $1.82(1.13-2.92) P<0.02$ \\
\hline Combination therapy: with $\mathrm{PI}$ & $\begin{array}{c}72(71) \\
\chi^{2}=1\end{array}$ & $\begin{aligned} & 29(29) \\
= & 0.001\end{aligned}$ & $2.15(1.38-3.35) P<0.02$ & $2.60(1.43-4.75) P<0.02$ \\
\hline
\end{tabular}

*Adjusted for all other variables in model. Cl, confidence interval; NS, not significant. 


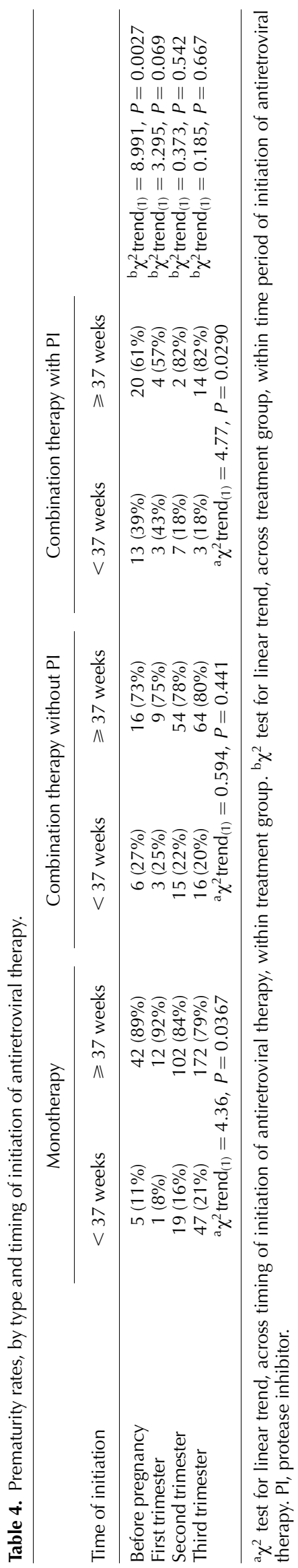

\section{Discussion}

These results confirm the reports from the Swiss Cohort that antiretroviral therapy in pregnancy, especially when involving PIs, increases risk of premature delivery [5]. Preliminary results from a meta-analysis of PACTG perinatal trials showed no increased risk of prematurity associated with combination antiretroviral therapy in pregnancy compared with no treatment or monotherapy [8]. The discrepancy between this and our findings may be due to different populations, or different approaches to analysis. We allow for other factors known to be associated with length of gestation in HIV-infected women, including maternal illicit drug use and immunosuppression and thus substantially increase the reliability of the estimated effect. Maternal CD4 count was a better predictor of prematurity than maternal viral load, with severe immunosuppression independently associated with a doubled risk of preterm labour. This is consistent with results from other studies $[13,15]$. The link between illicit drug use and prematurity in both HIV-infected and non-infected pregnant women is well established [16,17], and was observed here.

A previous finding in the ECS was that zidovudine monotherapy increased length of gestation but this effect was only marginally significant [12]. In this larger combined dataset, two years on, zidovudine monotherapy no longer had an effect on duration of pregnancy. However, interestingly, the risk of prematurity in this group was highest when zidovudine was introduced in the third trimester. The crude preterm delivery rates reported here of $17 \%$ for women on monotherapy and $16 \%$ among those untreated are broadly similar to the 19\% rate reported in an American cohort, where onethird of mothers received zidovudine monotherapy during pregnancy [18]. However, our crude prematurity rates of 22 and $29 \%$ for women on combination therapy without and with PIs respectively, are higher than the $20 \%$ rate reported in a review of 76 completed pregnancies in the US in which PIs were taken [19].

The finding that women on combination therapy and receiving treatment when their pregnancy was confirmed had double the risk of premature delivery compared to those who started therapy within the last trimester may shed some light on the underlying mechanisms. The fact that infants' birthweight was generally appropriate for their gestational age implies an effect on the mother rather than on uteroplacental function. The association we report between combination therapy with PI and prematurity may indicate an effect of these drug combinations over and above that on maternal HIV viral load. Further research may be indicated to explore other pregnancy outcomes, such as spontaneous abortions, in HIV-infected women on combination therapy. 


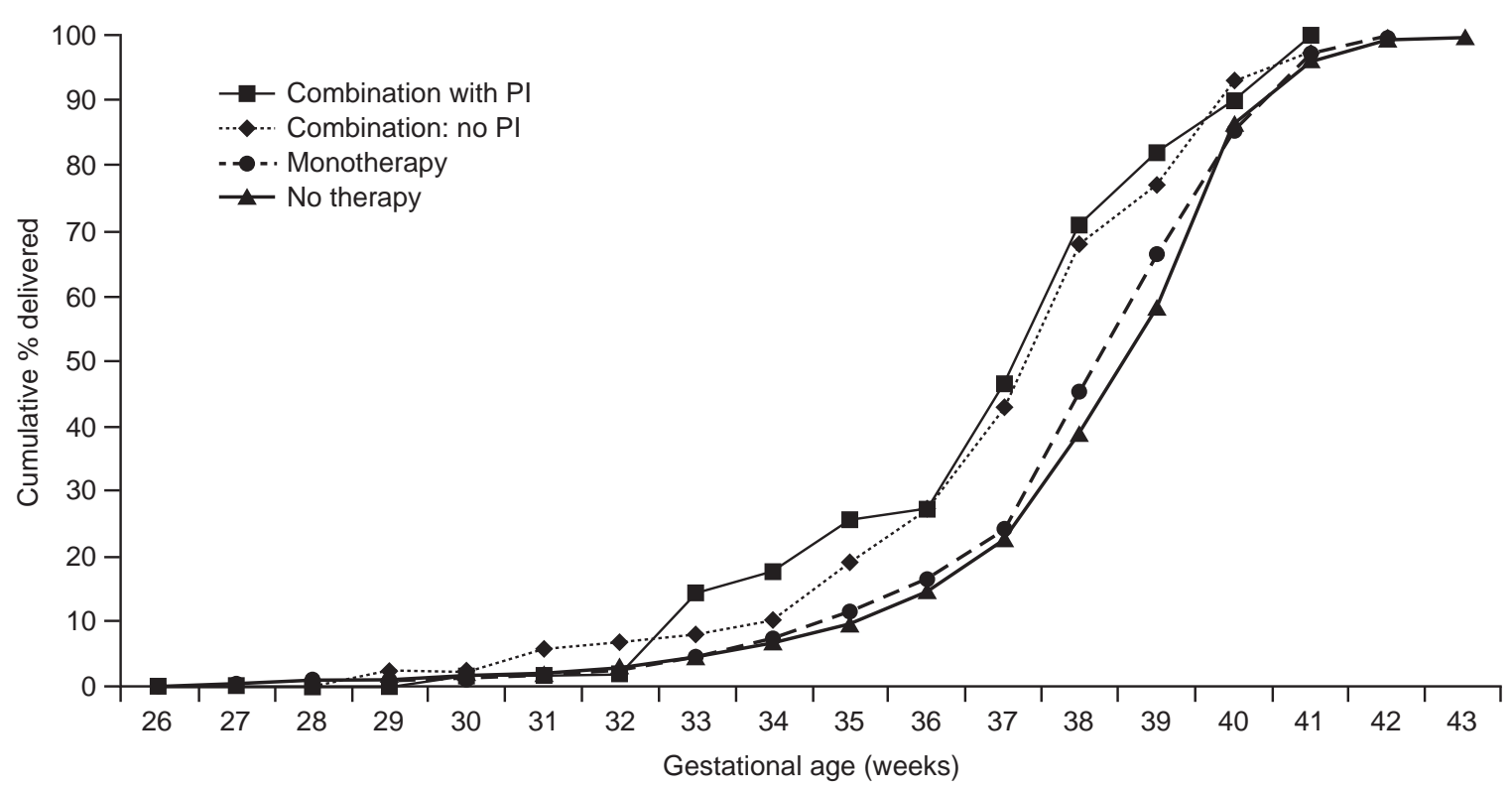

Fig. 1. Cumulative distribution of gestational age at delivery, by treatment group.

Vertical transmission rates are substantially reduced with use of elective caesarean section delivery, prophylactic antiretroviral therapy and formula-feeding [2-4,6,7, 20]. Conversely, prematurity is associated with a twoto three-times increased risk of mother-to-child transmission $[2,20,21]$. There may therefore be a smaller reduction in the overall vertical transmission risk if increasing numbers of infants of HIV-infected mothers on combination therapy are born prematurely. However, our results also suggest that such an effect would be limited to infants of mothers who started combination therapy with PI before pregnancy or during the first trimester.

In terms of morbidity and health service needs, degree of prematurity is more important than whether an infant is classified as premature or term. There was a 2.5-times increased risk of premature delivery in women on combination therapy with PIs, and $6 \%$ of their infants were born at less than 32 weeks gestation (versus approximately $2 \%$ for the other groups), when risk of postnatal problems are greatest [22,23]. The main implications of our findings relate to management of pregnancy in women on combination therapy, notably mode of delivery. Following European guidelines [1] all HIV-infected pregnant women should be offered an elective caesarean section to reduce the vertical transmission risk [24]. The risk following an emergency caesarean section is similar to that associated with vaginal delivery [4,24], although duration of rupture of membranes is an independent risk factor for mother-to-child transmission [3,20]. Our findings raise the question of whether the timing of elective caesarean section for women on combination therapy should be brought forward. In our cohort, if all women on combination therapy with PIs were delivered by elective caesarean section at 36 weeks, an additional $19 \%$ of infants would avoid vaginal or emergency caesarean section delivery. Such a change in practice would have to be weighed against the risks associated with earlier gestational age, such as lower birthweight and increased respiratory morbidity.

An HIV-infected woman of child-bearing age is in the unique position of making treatment decisions which will not only impact on her own health, but may also affect her future children [1,8]. Our findings highlight the need for health care providers to discuss future plans with HIV-infected women when deciding what kind of therapy to initiate. For women keen to start a family and without clinical or immunological indications for combination antiretroviral therapy, it may be prudent to defer starting combination therapy until after the first trimester of pregnancy.

\section{Acknowledgments}

We would like to acknowledge the help we have had from Mrs K Bennett and Dr Simona Fiore (London). We thank Prof L Chieco-Bianchi, Prof F Zacchello, Dr R D'Elia, Dr AM Laverda, Dr S Cozzani, Dr C Cattelan, Dr A Mazza, Prof B Grella, Dr AR Del Mistro, Dr V Giacomet, Dr O Rampon, Mrs S Oletto (Padua); Dr Cornelia Feiterna, Dr Ralf Weigel (Berlin); Dr S Burns, Dr N Hallam, Dr PL Yap, Dr J Whitelaw (Edinburgh); Dra B Sancho, Dr G Fontan-Casanego (Madrid); Dr F Asensi, Dr MC Otero, Dr A Perez Tamarit, Dr A Gonzalez Molina, Dr M Gobernado, Dr 
JL Lopez, Dr J Cordoba (Valencia); Dr G Mulder, Mevr T Kosten, Mevr M.C.A. van Leeuwen, the participants of the Dutch collaborative study of HIVinfected women and their children (Amsterdam); Ms C Ottenblad, Dr K Elfgren, Dr L Navér, Dr G LidinJanson, Dr B Anzén, Dr U Ewald, Dr A C Lindholm, Prof A Sönnerborg, Dr K Gyllensten, Dr PO Pehrsson (Sweden); Dr G Di Siena, Dr E Pontali, Dr F Fioredda, Prof M F Pantarotto, G Mantero, Dr S Anfossi, Dr S Boni (Genoa); Dr A Hottard, Dr M Poncin, Dr S Sprecher, Dr B Lejeune, Dr G Zississ, Prof N Clumeck (Brussels); Dr J Llorens, Dr M Iglesias (Hospital del Mar, Barcelona), Dr B Martinez de Tejada, Dr L Zamora, Dr R Vidal (Hospital Clinic, Barcelona), Dr G Zucotti (Ospedale San Paolo, Milano); Dr M Carla Re (Bologna); Dr C Christini, Dr F Castelli, Dr A Rodella (Brescia); Dr I Quinti, Prof A Pachí (Roma); Dr G Noia (Roma); Prof PA Tovo, Dr C Gabiano (Turino); Dr A Maccabruni, (Pavia); Dr G Ferraris, (Clinica Mangiagalli, Milano); Dr E Pagliaro, Dr M T Melisi (Naples).

Sponsorship: The Swiss Mother + Child HIV Cohort Study (MoCHiV) has been financed by the Swiss Federal Office of Health (Grants no 96-7257 and 97-7380) and the National Science Foundation (Grant no 3345062041). The European Collaborative Study is a concerted action of the European Commission (Biomed II PL 97 2005). The Medical Research Council (UK) provides support to the coordinating centre. Collaborating Centres were supported by grants from the Ministero della Sanita - Istituto Superiore di Sanita, progetto AIDS (Padua, Genoa); the Medical Research Council (UK), the AIDS Virus Education Research Trust, the Scottish Office Home and Health Department (Edinburgh); Praeventiefonds number 28-1704 (Amsterdam); Bundesminister fur Gesundheit (Berlin); Fonds Houtman, Office de la Naissance et de L'Enfance, Communaute Francaise de Belgique (Brussels), and the Swedish Medical Research Council (Stockholm).

\section{References}

1. Tovo P-A, Newell ML, Mandelbrot L, Semprini A, Giaquinto C. Recommendations for the management of HIV infected women and their infants - A European Consensus. Luxembourg: European Commission; 1999,1-37.

2. European Collaborative Study. Maternal viral load and vertical transmission of HIV-1: an important factor but not the only one. AIDS 1999, 13:1377-1385.

3. Mandelbrot L, Le Chenadec J, Berrebi A, et al. Perinatal HIV-1 transmission - interaction between zidovudine prophylaxis and mode of delivery in the French perinatal cohort. JAMA 1998, 280:55-60.

4. Kind C, Rudin C, Siegrist C-A, et al. Prevention of vertical HIV transmission: additive protective effect of elective Cesarean section and zidovudine prophylaxis. AIDS 1998, 12:205-210.

5. Lorenzi P, Spicher VM, Laubereau B, et al. Antiretroviral therapies in pregnancy: maternal, fetal and neonatal effects. AIDS 1998, 12:F241-F247.

6. Blattner W, Cooper E, Charurat M, et al. Effectiveness of potent antiretroviral therapies on reducing perinatal transmission of
HIV-1. XIII International Conference on AIDS. Durban, 9-14 July 2000 [abstract LbOr4].

7. Thorne, C for the European Collaborative Study. Antiretroviral therapy and caesarean section to reduce vertical transmission of HIV in Europe. XIII International Conference on AIDS. Durban, 9-14 July 2000 [abstract MoOrC240].

8. US Public Health Service Task Force. Recommendations for the use of antiretroviral drugs in pregnant women for maternal health and reducing perinatal HIV-1 transmission in the United States. MMWR 2000, 47:1-31.

9. Blanche $S$, Tardieu M, Rustin $P$, et al. Persistent mitochondrial dysfunction and perinatal exposure to antiretroviral nucleoside analogues. Lancet 1999, 354:1084-1089.

10. Hanson I C, Antonelli A, Sperling RS, et al. Lack of tumors in infants with perinatal HIV-1 exposure and fetal/neonatal exposure to zidovudine. J Acquir Immune Defic Syndr Hum Retrovirol 1999, 20:463-467.

11. Antiretroviral Pregnancy Registry Advisory Committee. The Antiretroviral Pregnancy Register January 1999. Interim Report 1999. Wilmington, North Carolina: Antiretroviral Pregnancy Registry.

12. European Collaborative Study. Is zidovudine therapy in pregnant HIV-infected women associated with gestational age and birthweight? AIDS 1999, 13:119-124.

13. European Collaborative Study. Vertical transmission of HIV-1: maternal immune status and obstetric factors. AIDS 1996, 10:1675-1681.

14. European Collaborative Study, Swiss HIV and Pregnancy Collaborative Study Group. Immunological markers in HIV infected pregnant women. AIDS 1997, 11:1859-1865.

15. O'Shea S, Newell ML, Dunn D, et al. Maternal viral load, CD4 cell count and vertical transmission of HIV-1. J Med Virol 1998, 54:113-117.

16. Mauri A, Piccione E, Deiana P, Volpe A. Obstetric and perinatal outcome in human immunodeficiency virus-infected pregnant women with and without opiate addiction. Eur J Obstet Gynecol Reprod Biol 1995, 58:135-140.

17. Boer K, Smit BJ, Van Huis AM, Hogerzeil HV. Substance use in pregnancy: do we care? Acta Paediatrica 1994, 83:65-71.

18. Martin $\mathrm{R}$, Boyer $\mathrm{P}, \mathrm{Hammill} \mathrm{H}$, et al. Incidence of premature birth and neonatal respiratory disease in infants of HIV-positive mothers. J Pediatr 1997, 131:851-856.

19. Morris A, Zorrilla C, Vajaranant $M$, et al. A review of protease inhibitors (PI) use in $\mathbf{8 9}$ pregnancies. Sixth Conference on Retroviruses and Opportunistic Infections. Chicago, January-February 1999 [abstract 686].

20. Simonds RI, Steketee R, Nesheim S, et al. Impact of zidovudine use on risk and risk factors for perinatal transmission of HIV. AIDS 1998, 12:301-308.

21. Mandelbrot L, Mayaux MJ, Bongain A, et al. Obstetric factors and mother-to-child transmission of human immunodeficiency virus type 1: The French perinatal cohorts. Am J Obstet Gynecol 1996, 175:661-667.

22. Copper RL, Goldenburg RL, Creasy RK, et al. A multicentre study of preterm birthweight and gestational age-specific neonatal mortality. Am J Obstet Gynecol 1993, 168:78-84.

23. Macfarlane A, Mugford M. Birth counts: statistics of pregnancy and child birth. Norwich: The Stationery Office; 2000.

24. The European Mode of Delivery Collaboration. Elective caesarean section versus vaginal delivery in preventing vertical HIV-1 transmission: a randomised clinical trial. Lancet 1999, 353:1035-1039

\section{Appendix}

The members of the Swiss Mother + Child HIV Cohort Study are: C. Aebi, M. Battegay, E. Bernasconi, K. Biedermann, J.-J. Cheseaux, G. Drack, P. Erb, M. Flepp , P. Francioli, H.J. Furrer, M.-P. Gianinazzi, T. Gyr, B. Hirschel, I. Hösli, I. Hug, O. Irion, K. Keller, C. Kind (Chairman of the MoCHiV Scientific Board subcommittee), B. Laubereau, U. Lauper (Chairman of the MoCHiV Clinical and Laboratory Subcom- 
mittee), P. Lorenzi, L. Matter, D. Nadal, L. Perrin, M. Rickenbach, C. Rudin (President of the MoCHiV, Basel UKBB, Römergasse 8, CH-4058 Basel), A. Schreyer, J. Schüpbach, A. Telenti, P. Vernazza, K. Wolf, D. Wunder, C.-A. Wyler.

The collaborating clinicians in the ECS are Dr C. Giaquinto, Dr E. Ruga, A. De Rossi (Universita degli Studi di Padova, Italy); Dr I. Grosch-Wörner, Dr K. Seel, Dr A. Schäfer (Charite Virchow-Klinikum, Berlin, Germany); Dr J. Mok (Royal Hospital For Sick Children, Edinburgh), Dr F. Johnstone (Dept of Obstetrics University of Edinburgh, UK); Dr J. Jimenez (Hospital 12 De Octubre, Madrid, Spain), Dr M.C. Garcia-Rodriguez, Dr I. Bates, Dr I. de José, Dr F. Hawkins, Dr C. Ladrón de Gevara, Dr J. Ma Peña, Dr J. Gonzalez Garcia, Dr J.R. Arribas Lopez (Hospital Infantil La Paz, Madrid); Professor F. Asensi-Botet, Dr M.C. Otero, Dr D. Pérez-Tamarit, Dr S. Ridaura, Dr P. Gregori, Dr R. de la Torre (Hospital La Fe, Valencia, Spain); Dr H. Scherpbier, M. Kreyenbroek, Dr K. Boer (Academisch Medisch Centrum, Amsterdam, The Netherlands); Dr A.B. Bohlin, Dr S. Lindgren, Dr A. Ehrnst, Dr E. Belfrage, Dr K. Lidman, Dr B. Christensson (Huddinge, Karolinska and Lund Hospitals, Sweden); Professor J. Levy, Dr M. Hainaut, Dr A. Peltier, Dr P. Barlow, Dr S. Wibaut, Ms M.C. Lecroart (Hospital St Pierre, Brussels, Belgium); Dr A. Ferrazin, Professor D. Bassetti, (Dept of Infectious Diseases, University of Genoa, Italy); Dr A. De Maria (Dept of Internal Medicine,
University of Genoa, Italy) Dr C. Gotta (Dept of Obstetrics \& Gynecology-Neonatology Unit, University of Genoa, Italy); Dr A. Mur, Dr A. Payà, Dr M. Viñolas, Dr M.A. López-Vilchez, Dr P. MartinezGómez, Dr R. Carreras (Hospital del Mar, Universidad Autónoma, Barcelona, Spain); Dr O. Coll, Dr C. Fortuny (Hospital Clinic, Barcelona, Spain); Dr J. Boguña (Hospital Sant Joan de Deu, Barcelona, Spain); Dr M. Casellas Caro (Hospital Vall D'Hebron, Barcelona, Spain); Dr Y. Canet (Hospital Parc Tauli de Sabadell, Barcelona, Spain); Professor G. Pardi, Dr M. Ravizza (Ospedale San Paolo, Milano, Italy); Dr B. Guerra, Dr M. Lanari, Dr S. Bianchi, Dr L. Bovicelli (Policlinico S Orsola, Bologna, Italy); Dr E. Prati, Professor M. Duse (Universita di Brescia, Brescia, Italy); Dr G. Scaravelli, Dr M. Stegagno (Universita La Sapienza, Roma, Italy); Dr M. De Santis (Universita Cattolica, Roma, Italy); Dr A.E. Semprini, Dr V. Savasi, Dr A. Viganò (Ospedale L. Sacco, Milan, Italy); Dr F. Ravagni Probizer, Professor A. Maccabruni (Policlinico S Matteo, Pavia, Italy); Dr A. Bucceri, Dr L. Rancilio (Clinica Mangiagalli and Clinica De Marchi, Milano, Italy); Dr G.P. Taylor, Dr H. Lyall (St Mary's Hospital, London); Ms Z. Penn (Chelsea and Westminster Hospital, London); Dr N.H. Valerius (Hvidovre Hospital, Denmark); Professor P. Martinelli, Drssa W. Buffolano, Drssa M. Sansone (II Policlinico, Naples, Italy); Dr C. Tibaldi, Dr N. Ziarati, Dr C. Benedetto (University di Torino, Italy); Dr T. Niemieç, Dr A. Horban (Centrum Diagnostyki I Terapii AIDS, Warsaw, Poland). 